\title{
Alveolar Rhabdomyosarcoma
}

National Cancer Institute

\section{Source}

National Cancer Institute. Alveolar Rhabdomyosarcoma. NCI Thesaurus. Code C3749.

A rapidly growing malignant mesenchymal neoplasm. It is characterized by the presence

of round cells with myoblastic differentiation and a fibrovascular stroma resembling an alveolar growth pattern. The tumor usually presents in the extremities. 